\title{
Application of the urinary S-phenylmercapturic acid test as a biomarker for low levels of exposure to benzene in industry
}

\author{
N J van Sittert, P J Boogaard, G D J Beulink
}

\begin{abstract}
Recently, the determination of S-phenylmercapturic acid (S-PMA) in urine has been proposed as a suitable biomarker for the monitoring of low level exposures to benzene. In the study reported here, the test has been validated in 12 separate studies in chemical manufacturing plants, oil refineries, and natural gas production plants. Parameters studied were the urinary excretion characteristics of S-PMA, the specificity and the sensitivity of the assay, and the relations between exposures to airborne benzene and urinary $S$ PMA concentrations and between urinary phenol and S-PMA concentrations. The range of exposures to benzene was highest in workers in chemical manufacturing plants and in workers cleaning tanks or installations containing benzene as a component of natural gas condensate. Urinary S-PMA concentrations were measured up to $543 \mu \mathrm{g} / \mathrm{g}$ creatinine. Workers' exposures to benzene were lowest in oil refineries and S-PMA concentrations were comparable with those in smoking or nonsmoking control persons (most below the detection limit of 1 to $5 \mu \mathrm{g} / \mathrm{g}$ creatinine). In most workers S-PMA was excreted in a single phase and the highest S-PMA concentrations were at the end of an eight hour shift. The average half life of elimination was $9 \cdot 0$ (SD 4.5) hours ( 31 workers). Tentatively, in five workers a second phase of elimination was found with an average half life of 45 (SD 4 ) hours.

A strong correlation was found between
\end{abstract}

Shell Internationale Petroleum Maatschappij BV, Health, Safety and Environment Division, Biomedical Services, PO Box 162, 2501 AN, The Hague, The Netherlands

N J van Sittert, P J Boogaard

Shell Nederland Raffinaderij/Shell Nederland Chemie BV, Biomedical Laboratory, PO Box 7000, 3000 HA Rotterdam, The Netherlands

N J van Sittert, G D J Beulink eight hour exposure to airborne benzene of 1 $\mathrm{mg} / \mathrm{m}^{3}(0 \cdot 3 \mathrm{ppm})$ and higher and urinary $S$ PMA concentrations in end of shift samples. It was calculated that an eight hour benzene exposure of $3.25 \mathrm{mg} / \mathrm{m}^{3}(1 \mathrm{ppm})$ corresponds to an average S-PMA concentration of $46 \mu \mathrm{g} / \mathrm{g}$ creatinine ( $95 \%$ confidence interval $41-50 \mu \mathrm{g} / \mathrm{g}$ creatinine). A strong correlation was also found between urinary phenol and S-PMA concentrations. At a urinary phenol concentration of $50 \mathrm{mg} / \mathrm{g}$ creatinine, corresponding to an eight hour benzene exposure of $32.5 \mathrm{mg} / \mathrm{m}^{3}$ $(10 \mathrm{ppm})$, the average urinary S-PMA concentration was $383 \mu \mathrm{g} / \mathrm{g}$ creatinine. In conclusion, with the current sensitivity of the test, eight hour time weighted average benzene exposures of $1 \mathrm{mg} / \mathrm{m}^{3}(0.3 \mathrm{ppm})$ and higher can be measured.

(British Journal of Industrial Medicine 1993;50:460-469)

The most often used method for the biological monitoring of exposure to benzene is the determination of urinary phenol concentrations. Phenol and its conjugates are the main metabolites in the urine after benzene exposure, whereas much smaller amounts of hydroquinone, catechol, trans:trans-muconic acid, and S-phenylmercapturic acid are excreted. ${ }^{1}$ Urinary phenol is a suitable biomarker for measuring occupational eight hour time weighted average (TWA) benzene exposures of $10 \mathrm{ppm}\left(32.5 \mathrm{mg} / \mathrm{m}^{3}\right)$ or greater. ${ }^{23}$ Several national and international authorities have recently advised reduction of occupational benzene exposure to lower concentrations. ${ }^{4-6}$ At airborne benzene concentrations below 6 ppm (eight hour TWA), urinary phenol is not a reliable biomarker for individual persons due to the lack of specificity of the method of measurement. ${ }^{3}$

Benzene concentrations in blood and in exhaled air have been used as specific and sensitive biomarkers for measuring both occupational and nonoccupational exposure to benzene. ${ }^{378}$ In occupational health surveillance, however, the use of urine as a sampling medium is preferred because it can be readily obtained by non-invasive means. 
Recently, assays have been developed by different groups for the determination of either S-phenylmercapturic acid (S-PMA) and trans:trans-muconic acid $(t, t-M A)$ in urine as biomarkers of higher specificity for benzene monitoring than urinary phenol..$^{9-12} \mathrm{~S}$ PMA is a marker for a detoxication pathway of benzene metabolism, and t,t-MA is produced by biotransformation of trans,trans-muconaldehyde, which is considered as one of the benzene metabolites responsible for its toxicity. ${ }^{1}$ The S-PMA test was useful for monitoring subjects exposed to eight hour TWA benzene concentrations as low as 1 ppm. ${ }^{9}$ For the $t, t-M A$ assay, the authors claimed that benzene exposure between 2.6 and $7 \mathrm{ppm}$ (eight hours) or greater could be measured. ${ }^{10-12}$

We have adopted the earlier published S-PMA method, ${ }^{9}$ and applied a modification of the assay to workers who had potential exposure to benzene in different industrial situations. The aims of the study were firstly to improve our knowledge of the kinetics of the urinary excretion of S-PMA as a function of time and secondly to determine the relation between occupational exposure to benzene and urinary excretion of S-PMA.

\section{Materials and methods}

POPULATIONS AND COLLECTION OF URINE AND AIRBORNE SAMPLES

To validate the S-PMA method, 12 studies in 10 locations (five countries) have been carried out since 1989 on workers who were potentially exposed to benzene during manufacturing and maintenance operations in chemical plants and in refineries and during pre-shutdown operations in natural gas installations. Urine samples were collected for S-PMA analyses in all studies and for phenol analyses in five studies. Benzene concentrations in the breathing zone of the workers were assessed by personal air sampling on the days of urine collection in nine studies.

For the estimation of normal values, S-PMA was also determined in urine samples of 48 control persons who were not occupationally exposed to benzene. This group comprised 28 non-smokers and 20 cigarette smokers.

Three surveys were carried out during operations in a chemical manufacturing site in The Netherlands.

Studies 1 and 2 were performed in 1989 and 1990 respectively in a chemical plant where benzene is used for the production of ethyl-benzene. Study 1 took place on 12 workers. Ten of them provided urine samples for S-PMA and phenol determination at the beginning and the end of the eight hour shift during three to five consecutive days and two of them during one day. Personal air sampling was carried out on 11 workers during the full time of each shift using passive dosimeters (3M gas diffusion badges, type 3500). The detection limit of airborne benzene concentrations for an eight hour sampling period was $0.5 \mathrm{mg} / \mathrm{m}^{3}$ (eight hour TWA). Study 2 was carried out on 23 workers who were asked to provide urine samples for S-PMA and phenol analyses at the beginning and the end of both the first and the fifth day of their working week. Some of the workers also provided urine on the second, third, and fourth day of the working week. Personal air sampling was carried out as in study 1 , but the detection limit of airborne benzene had been lowered to $0.1 \mathrm{mg} / \mathrm{m}^{3}$ (eight hour TWA).

Study 3 took place in 1991 and 1992 on 156 workers who provided urine for S-PMA and phenol analyses at the end of a shift on a random basis after activities where peak exposures to benzene might have occurred, for example, repair work on pumps. Personal air sampling was not performed.

Six surveys have been carried out on workers in oil refineries located in Germany, The Netherlands, Norway, Saudi Arabia, and Sweden. Study 4 took place in 1989 on three workers and one laboratory technician who provided urine for S-PMA and phenol analyses at the beginning and the end of each shift during four consecutive days. Personal air sampling was carried out with $3 \mathrm{M}$ gas diffusion badges, type 3500 . The detection limit was $0.1 \mathrm{mg} / \mathrm{m}^{3}$ (eight hour TWA).

A similar investigation (study 5) took place in 1990 on three workers and one laboratory technician who provided urine samples for S-PMA determination at the beginning and the end of the eight hour shift during five consecutive days. Personal air sampling was carried out using $3 \mathrm{M}$ gas diffusion badges. The detection limit was $0.1 \mathrm{mg} / \mathrm{m}^{3}$ (eight hour TWA). Study 6 was performed in 1990 in the same refinery as in study 5 on 16 workers who were involved in the cleaning and maintenance of a tank used for the storage of natural gas condensate, which may contain benzene concentrations up to $10 \%$. Six workers provided urine at the beginning and about one to two hours before the end of the eight hour shift during the first week of the operations (study 6 I), six workers during the second week (study 6 II), and four workers during the third week (study 6 III). Personal air sampling was carried out as in study 5 .

Study 7 was performed in 1990 on 23 persons who provided urine samples for S-PMA analyses at the beginning and the end of both the first and the last day of a work week. The 23 persons were employed as refinery workers (12 persons), maintenance workers, mechanics, inspectors, safety guards, instrument technicians, and laboratory technicians. Air sampling was carried out by personal sampler pumps (flow rate $25 \mathrm{ml} / \mathrm{min}$ ), with charcoal as adsorbent. The detection limit was $0.02 \mathrm{mg} / \mathrm{m}^{3}$.

Study 8 was performed in 1990 on 18 persons who provided urine samples for S-PMA analyses at the beginning and the end of both the first and the last 
day of a work week. Air sampling was by personal sampler pumps (flow rate between 40 and $80 \mathrm{ml} /$ $\mathrm{min}$ ), with charcoal as adsorbent. The detection limit was $0.01 \mathrm{mg} / \mathrm{m}^{3}$ (eight hour TWA). The 18 persons in this study included workers in the aromatics plant (benzene, toluene, and xylene), workers engaged in the blending of refinery products, workers engaged in road tanker and ship loading of refinery products, mechanics, and a laboratory technician. Study 9 took place in 1991 on six persons involved in the cleaning and maintenance of an aromatics plant in a refinery. Urine samples for S-PMA determination were collected at the beginning and the end of the eight hour shift during 10 days. Personal air sampling was not carried out.

Three studies were on workers engaged in cleaning and maintenance of installations for the production of natural gas. These installations may contain residues of benzene.

Study 10 was performed in 1990 on 13 workers engaged in pre-shutdown operations on a gas production platform in the North Sea. Urine samples for S-PMA and phenol analyses were provided at the beginning of the operations and at the end of the fifth, sixth, or seventh working day (12 hour shift). Personal air sampling was not carried out on the days of urine sampling.

A similar study (study 11) took place in 1991 on nine workers who provided urine for S-PMA analyses at the beginning and the end of the 12 hour shift during two or three consecutive days. Personal air sampling was by personal sampler pumps (flow rate $100 \mathrm{ml} / \mathrm{min}$ ), with charcoal as adsorbent. The detection limit of airborne benzene was $0.1 \mathrm{mg} / \mathrm{m}^{3}$ (12 hour TWA).

Study 12 was performed in 1991 on eight workers engaged in pre-shutdown operations in a gas installation plant in The Netherlands. Urine samples were collected at the beginning and at the end of the eight hour shift during five consecutive days and analysed for S-PMA. Airborne benzene concentrations were determined as in study 11 .

In all studies, urine samples were collected in polythene bottles and acidified to $\mathrm{pH} 2$ with $6 \mathrm{M}$ hydrochloric acid. Stability studies of S-PMA and phenol in urine had shown that under these conditions concentrations did not change if stored at room temperature or $4^{\circ} \mathrm{C}$ for at least one month. The samples were transported to the Shell Biomedical Laboratory, Rotterdam, for S-PMA, phenol, and creatinine determination. Urinary creatinine was determined to adjust for the dilution of urine samples caused by differences in fluid intake between workers.

Personal air sampling and benzene analyses were performed by local staff.

DETERMINATION OF URINARY S-PMA

The method described is a modification of the previously published assay of Stommel et al. ${ }^{9} \mathrm{~A} 1.0$ $\mathrm{ml}$ aliquot of urine containing $150 \mathrm{ng}$ added Sbenzylmercapturic acid (S-BMA) as an internal standard (Janssen Chimica, Belgium) was extracted with $4.0 \mathrm{ml}$ ethyl acetate. After centrifugation, the ethyl acetate layer was evaporated to dryness under a gentle stream of nitrogen in a water bath at $45^{\circ} \mathrm{C}$ and the residue was dissolved in $2.0 \mathrm{ml}$ methylating agent (methanol/1.25 M HCl). This agent was prepared by passing $46 \mathrm{~g} \mathrm{HCl}$ gas through 11 methanol. After methylation of S-PMA and S-BMA at room temperature for 30 minutes, the solution was evaporated to dryness under a gentle stream of nitrogen at $45^{\circ} \mathrm{C}$ and dissolved in $1.0 \mathrm{ml}$ dichloromethane. The sample was analysed by gas chromatography-mass spectrometry selected ion recording (Hewlett Packard mass selective detector, model HP 5971 interphased with a Hewlett Packard HP 5890 series II gaschromatograph, equipped with an automatic sampler model HP 7673). A fused silica capillary column was used $(60 \mathrm{~m} \times 0.22 \mathrm{~m}$ ) coated with DB-1 (Durabond, film thickness $0 \cdot 1 \mu \mathrm{m})$. The carrier gas was helium at $170 \mathrm{kPa}$ (flow of about $1 \mathrm{ml} / \mathrm{min}$ ). The injector ternperature was $250^{\circ} \mathrm{C}$ and the oven temperature programme $35^{\circ} \mathrm{C}$ for 1 minute, then $10^{\circ} \mathrm{C}$ /minute steps up to $300^{\circ} \mathrm{C}$, then constant at $300^{\circ} \mathrm{C}$ for 7.5 minutes. The injection volume was $1 \mu \mathrm{l}$ splitless. For quantification of S-PMA the ions at $\mathrm{m} / \mathrm{z} 194$ (fragment of S-PMA methylester) and at m/z 176 (fragment of S-BMA methylester) were monitored.

For calibration, a series of S-PMA standards in fresh control urine samples $(5-1000 \mu \mathrm{g} / \mathrm{l})$ were analysed together with the urine samples. The amount ratio of the methylesters of S-PMA and of the internal standard S-BMA were plotted against the response ratio of $\mathrm{m} / \mathrm{z} 194$ and $\mathrm{m} / \mathrm{z} 176$. The recovery of added S-PMA was about $80 \%$. The coefficient of variation of replicate analyses $(n=8)$ was $3.9 \%$ at a spiked concentration of $66 \mu \mathrm{g} / 1$ and $20 \%$ at a spiked concentration of $7 \mu \mathrm{g} / \mathrm{l}$. The limit of detection was 1-5 $\mu \mathrm{g} / 1$ depending, for example, on matrix effects, condition of the mass selective detector, and experience of the operator. Results of urinary S-PMA measurements were expressed in $\mu \mathrm{g} / \mathrm{g}$ creatinine. With this procedure, 20 to 30 urine samples could be analysed in one day.

DETERMINATION OF URINARY PHENOL AND CREATININE The gas chromatographic method of Van Haaften and Sie was used for the determination of urinary phenol concentrations. ${ }^{13}$ Creatinine was determined by the Jaffe method. ${ }^{14}$

\section{BENZENE IN AIR}

The benzene vapour adsorbed on the charcoal tubes or the $3 \mathrm{M}$ badges during air sampling was desorbed by carbon disulphide and the solution was analysed with a gas chromatograph equipped with a flame 
ionisation detector using National Institute for Safety and Health (NIOSH) standard methods. ${ }^{15}$

\section{CALCULATIONS AND STATISTICS}

Urinary elimination rate constants (ks) of S-PMA were determined from workers who had provided urine samples at the beginning and the end of a shift during two or more consecutive days. The elimination rate constants were calculated assuming completed absorption and first order elimination kinetics during the urine collection period, from the formula $\ln (\mathrm{C}(\mathrm{a}) / \mathrm{C}(\mathrm{e}))=-\mathrm{k}(\mathrm{t}(\mathrm{a})-\mathrm{t}(\mathrm{e}))$, where $\mathrm{C}(\mathrm{e})$ denotes the concentration S-PMA in urine samples collected at the end of a shift $(t(e))$ and $C(a)$ the urinary concentration at the beginning of the next day shift $(t(a))$. Occasionally higher S-PMA concentrations were found at the beginning of the next day shift. In that case $\mathrm{C}(\mathrm{e})$ denotes the urinary S-PMA concentration in samples collected at the beginning of that shift and $\mathrm{C}(\mathrm{a})$ at the end of that shift. In the last case, $\mathrm{k}$ was only calculated if workers had no detectable exposure to benzene during that working day. In all cases $\mathrm{C}(\mathrm{e})$ had to be above $10 \mu \mathrm{g} / \mathrm{g}$ creatinine (at least twice the analytical detection limit). Data that fulfilled these criteria were available from 31 workers. If $k$ could be calculated more than once for a worker the data were averaged. From the average $k$, the corresponding half life $\left(t^{\frac{1}{}}\right)$ of elimination was calculated for each worker from the formula $t^{\frac{1}{}}=\ln 2 / k$.

For 19 workers sufficient urine samples were collected during consecutive days to construct a urinary excretion $v$ time plot. Cumulative excretion of S-PMA was estimated from the area under the curve (AUC) of this plot. In the absorption phase the linear and in the elimination phase the logarithmic trapezoidal rule was used for the calculation of the AUC using the formula:

$$
\operatorname{AUC}(e-a)=\frac{[C(e)-C(a)] .[t(a)-t(e)]}{\ln [C(e)]-\ln [C(a)]} \times 0.0625
$$

where 0.0625 is the average urinary volume ( $1 /$ hour), $\mathrm{C}(\mathrm{e})$ denotes the urinary S-PMA concentration at time $t(e)$, and $C(a)$ at time $t(a)$ of the elimination phase, $\mathrm{C}(\mathrm{e})>\mathrm{C}(\mathrm{a})$.

For the assessment of the percentage of the respiratory benzene dose that is excreted as urinary $S$ PMA, the absorbed benzene dose was calculated using the formula: CRV, where $C$ is the benzene airborne concentration $\left(\mathrm{mg} / \mathrm{m}^{3}\right), R$ is the retention of inhaled benzene, which is estimated as $47 \%,{ }^{16}$ and $V$ is the respiratory volume during an eight hour working day $\left(10 \mathrm{~m}^{3}\right)$.

The relation between airborne benzene and urinary S-PMA was assessed by linear regression analysis. Two confidence intervals (CIs) were calculated-namely, the CIs for the mean value of benzene as a function of urinary S-PMA for a group and for an individual observation. The relation between urinary phenol and S-PMA was also assessed. For all calculations the mainframe version of the SAS software package (version 6.06) was used.

\section{Results \\ S-PMA IN BENZENE EXPOSED AND CONTROL POPULATIONS}

Concentrations of S-PMA in the urine of 48 control persons ( 28 non-smokers and 20 cigarette smokers), who had not been occupationally exposed to benzene, were in the range of $<2$ to $6 \mu \mathrm{g} / \mathrm{g}$ creatinine (median $<2 \mu \mathrm{g} / \mathrm{g}$ creatinine). Smoking (up to 30 cigarettes a day) had no influence on the S-PMA concentrations. Baseline urinary S-PMA concentrations at the beginning of the working week had been determined for 127 workers in 11 of the 12 locations. In $25 \%$ of the samples S-PMA concentrations were above the analytical limit of detection of $5 \mu \mathrm{g} / \mathrm{g}$ creatinine and in $3.9 \%$ of the samples S-PMA concentrations were higher than $10 \mu \mathrm{g} / \mathrm{g}$. The highest concentrations were found in two workers of study $11(28$ and $19 \mu \mathrm{g} / \mathrm{g})$. It seemed that these workers had been on the gas production platform the previous day and therefore might have been exposed to benzene. Their urinary S-PMA concentrations at the beginning of the working week therefore did not represent true baseline values.

Table 1 shows that during operations with exposures to benzene in chemical manufacturing sites in The Netherlands (studies 1, 2, and 3), increased S-PMA concentrations have been found in samples at the end of the shift compared with samples at the beginning of the shift. Median S-PMA concentrations in samples at the end of the shift, however, were close to the analytical limit of detection, reflecting the generally low benzene exposures. Airborne benzene concentrations ranged from $<0.5$ to $4.0 \mathrm{mg}$ / $\mathrm{m}^{3}$ in study 1 and from $<0.1$ to $11.3 \mathrm{mg} / \mathrm{m}^{3}$ in study 2. Corresponding urinary S-PMA concentrations in samples at the end of the shift ranged from $<5$ to 41 $\mu \mathrm{g} / \mathrm{g}$ creatinine in study 1 and from $<5$ to $229 \mu \mathrm{g} / \mathrm{g}$ in study 2 .

The highest S-PMA concentrations (up to 543 $\mu \mathrm{g} / \mathrm{g}$ creatinine) were found in some samples provided by workers on a random basis during manufacturing or maintenance activities where peak exposures to benzene occurred.

In refinery workers (studies 4,5 , and 7 ) during normal operations no increased urinary S-PMA concentrations were found in samples at the end of the shift compared with the beginning of the shift. Airborne benzene concentrations ranged from $<0.05$ to $1.9 \mathrm{mg} / \mathrm{m}^{3}$ in study 4 , from $<0.1$ to 0.12 $\mathrm{mg} / \mathrm{m}^{3}$ in study 5 , and from $<0.02$ to $1.8 \mathrm{mg} / \mathrm{m}^{3}$ in study 7 . 
In the refinery with an aromatics plant (study 8), airborne benzene measured during two days was in the range of $<0.01-1.3 \mathrm{mg} / \mathrm{m}^{3}$. The median S-PMA concentration in samples at the end of the first working day was below the analytical detection limit of $5 \mu \mathrm{g} / \mathrm{g}$ creatinine (range: $<5-43 \mu \mathrm{g} / \mathrm{g}$ ). Surprisingly, the highest S-PMA concentrations (93 and 80 $\mu \mathrm{g} / \mathrm{g}$ ) were in the urine provided by two workers at the beginning of the last working day. These workers had airborne benzene exposure below $0.2 \mathrm{mg} / \mathrm{m}^{3}$ during the last working day and their S-PMA concentrations dropped to 17 and $57 \mu \mathrm{g} / \mathrm{g}$ respectively in urine samples collected at the end of the shift. Normally, the high urinary S-PMA concentrations were found in urine samples at the end of a working day compared with samples at the beginning of the day. This was best shown in six workers (study $6 \mathrm{I})$ who had S-PMA concentrations in samples collected at the end of the shift that ranged from 25 to $107 \mu \mathrm{g} / \mathrm{g}$ creatinine (median $38 \mu \mathrm{g} / \mathrm{g}$ ). Airborne benzene concentrations ranged from 0.5 to $13.6 \mathrm{mg}$ / $\mathrm{m}^{3}$ (median $5.0 \mathrm{mg} / \mathrm{m}^{3}$ ). During one specific day, urinary S-PMA concentrations in two workers (study 6 III) increased from $6 \mu \mathrm{g} / \mathrm{g}$ in samples at the beginning of the shift to 30 and $67 \mu \mathrm{g} / \mathrm{g}$ in samples at the end of the shift. Corresponding airborne benzene concentrations (eight hour TWA) were 0.6 and 0.3 $\mathrm{mg} / \mathrm{m}^{3}$, which is much lower than expected from urinary S-PMA concentrations. Benzene air concentrations, however, were only measured during three hours of the working day and therefore the reported eight hour TWA air exposures may have been underestimated.

During a clean out and maintenance stop of an aromatics plant in a refinery (study 9), no increased concentrations of urinary S-PMA were found in comparison with baseline values.

Workers engaged in cleaning activities of installations for the production of natural gas had increased urinary S-PMA concentrations in samples at the end of the shift (studies 10-12). The highest urinary SPMA concentrations were found in workers of study 10 , who collected samples at the end of the fifth, sixth, or seventh working day. Concentrations ranged from 11 to $153 \mu \mathrm{g} / \mathrm{g}$ creatinine. No airborne exposures $i 0$ benzene were measured during the day of urine collection. Concentrations measured on other days, however, ranged from $2 \cdot 6$ to $23 \mathrm{mg} / \mathrm{m}^{3}$.

Table 1 Airborne benzene concentrations and $S$-phenylmercapturic acid (S-PMA) concentrations in urine samples collected at the beginning $(B)$ and at the end $(E)$ of the shift

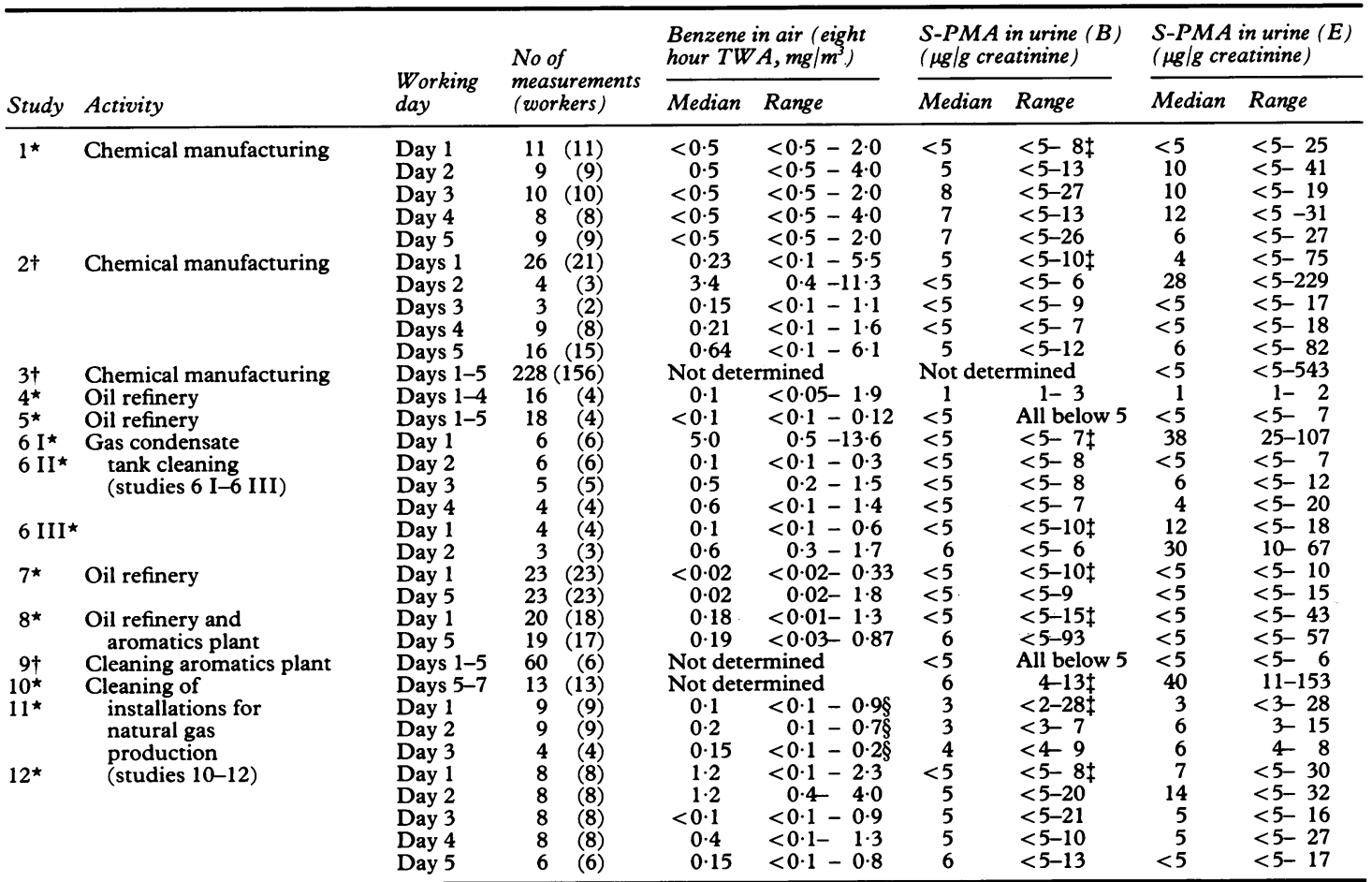

*One working week.

$\uparrow$ More than one working week.

$\ddagger$ Concentrations at the beginning of the working week.

$\$ 12$ hour shift. 
In studies 11 and 12 , most benzene exposures were below $3.25 \mathrm{mg} / \mathrm{m}^{3}$ (1 ppm). Nevertheless, increased S-PMA concentrations were seen in samples at the end of the shift compared with the beginning of the shift (see table 1).

URINARY EXCRETION PROFILES OF S-PMA

Figure 1 shows the time courses for urinary S-PMA and phenol excretions during one working week in relation to airborne benzene exposures for two workers (study 1). For eight hour TWA exposures to airborne benzene equal to or higher than $1 \mathrm{mg} / \mathrm{m}^{3}$ $(0.3 \mathrm{ppm})$, an increase of urinary S-PMA concentration was found in samples collected from worker $A$ at the end of the shift, followed by a return close to baseline S-PMA concentrations in samples at the beginning of the next shift. A delayed excretion of SPMA was seen in worker B. After benzene exposures on days 1 and 2, S-PMA concentrations in samples collected at the beginning of the next day's shifts (days 2 and 3 ) were higher than in samples collected at the end of the shift. After a day without detectable airborne exposure to benzene (day 3), S-PMA in the sample collected at the beginning of the next day shift (day 4) had returned to baseline.

Most workers in the studies reported here had SPMA excretion profiles like that of worker A. For the excretion of urinary phenol, figure 1 shows that for worker $A$ the excretion profile was similar to that of S-PMA. The lack of specificity of urinary phenol was shown in worker $B$, whose urinary phenol concentration increased to about $40 \mathrm{mg} / \mathrm{g}$ creatinine on day 3 whereas there was no detectable exposure to benzene.

\section{URINARY ELIMINATION RATE CONSTANTS AND HALF} LIVES OF S-PMA

In most workers, S-PMA was excreted in a single phase, but in some workers a biphasic excretion was found. The $k$ value for the first (fast) phase was calculated from 52 data points of 31 workers. The median $k$ of the fast phase was $0.076 \mathrm{l} /$ hour, corresponding with an apparent half life of elimination $\left(t^{\frac{1}{3}}\right)$ of 9.6 hours (mean 9.0 (SD 4.5) hours). The interindividual coefficient of variation in $\mathrm{t}^{\frac{1}{2}}$ was $50 \%$ and the intraindividual variation $37 \%$.

The median $k$ of the slow phase was $0.0161 /$ hour and was calculated from six data points of five workers. The corresponding half life was $\mathbf{4 3}$ hours (mean: 45 (SD 4) hours).

URINARY S-PMA EXCRETION AS PERCENTAGE OF DOSE For 19 workers urinary excretion $v$ time plots could be constructed that allowed an estimation of the cumulative excretion of S-PMA. From this cumulative excretion and the estimated respiratory absorbed dose of benzene, it was calculated that the average percentage of dose excreted in urine as $S$ PMA was $0.11 \%$ (range $0.05 \%-0.29 \%$ ).

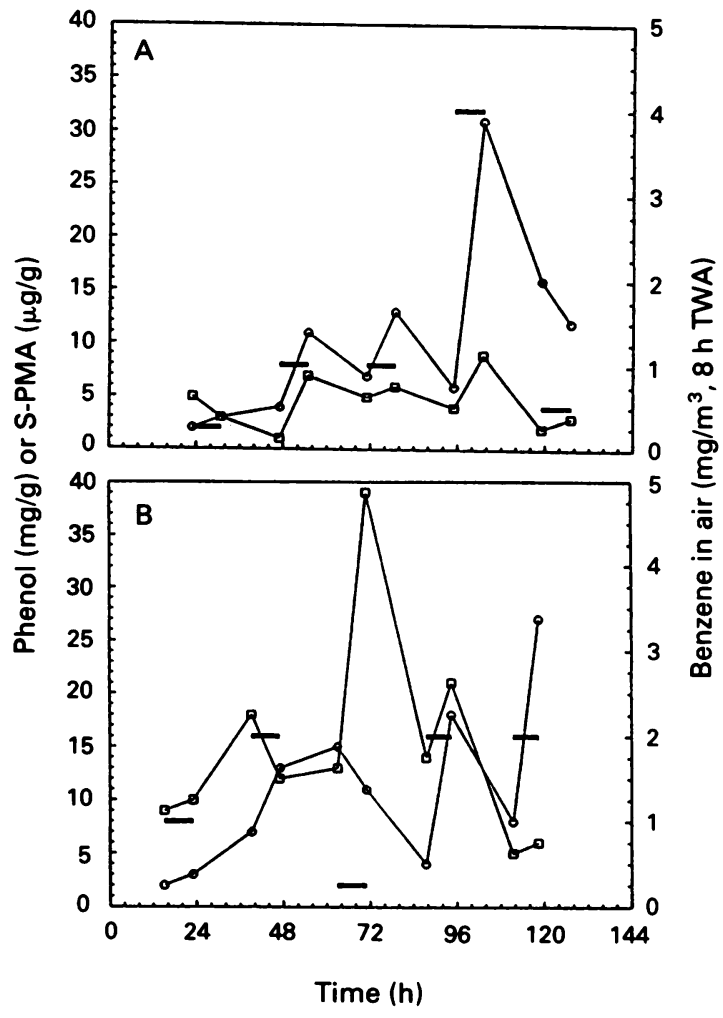

Figure 1 Urinary excretion of S-PMA (circles) and phenol (squares)) in two workers ( $A$ and $B$ ) after exposure to benzene (concentration and exposure period are indicated by bars) during five consecutive days.

\section{CORRELATION OF AIRBORNE BENZENE AND URINARY} S-PMA

The relation between eight hour TWA exposures to airborne benzene and urinary S-PMA concentrations in samples collected at the end of the shift could be determined from data in studies 1, 2, $6 \mathrm{I}$, and 12 . In the other studies exposures to airborne benzene were too low to study such a relation. Data from workers who stated in a questionnaire that they wore respiratory protection during the monitoring period were excluded from the statistics. In cases where more than one data point had been generated for a worker during a specific study, the data point with the highest airborne benzene concentration and corresponding S-PMA concentration was used for the assessment of the ultimate regression line and correlation coefficient for that study (table 2: all days). Highly significant correlations were found between exposures to airborne benzene and urinary S-PMA in all four studies (table 2). From the regression lines it was calculated that at an eight hour TWA benzene exposure of $1 \mathrm{ppm}\left(3.25 \mathrm{mg} / \mathrm{m}^{3}\right)$, the average S-PMA concentrations in the four studies 
Table 2 Relations between airborne benzene (eight hour $T W A$ ) concentrations $\left(Y ; m g / m^{3}\right.$ ) and $S$-phenylmercapturic acid $(S-P M A)$ concentrations in urine samples collected at the end of the shift $(X ; \mu g / g$ creatinine) in the various studies

\begin{tabular}{|c|c|c|c|c|c|c|}
\hline \multirow[b]{2}{*}{ Study } & \multirow[b]{2}{*}{ Working day } & \multirow{2}{*}{$\begin{array}{l}\text { No of } \\
\text { workers }\end{array}$} & \multicolumn{3}{|c|}{ Regression line $Y=a X+b$ and correlation coefficient } & \multirow{2}{*}{$\begin{array}{l}\text { Average } S-P M A \text { concentration } \\
\text { ( } \mu g / g \text { creatinine) at } \\
\text { eight hour airborne benzene } \\
\text { exposure of } 3.25 \mathrm{mg} / \mathrm{m}^{3}\end{array}$} \\
\hline & & & $a$ & $b$ & $r$ & \\
\hline \multirow[t]{4}{*}{$1^{\star}$} & Day 1 & 10 & 0.056 & $0 \cdot 16$ & 0.835 & 55 \\
\hline & Day 4 & 7 & 0.138 & -0.76 & 0.921 & 29 \\
\hline & Day 5 & 8 & 0.070 & -0.07 & 0.951 & 47 \\
\hline & All days+ & 11 & $0 \cdot 103$ & $0 \cdot 26$ & 0.697 & 29 \\
\hline \multirow{2}{*}{$2+$} & Day 5 & 13 & 0.061 & $0 \cdot 11$ & 0.918 & 51 \\
\hline & All days + & 23 & 0.068 & 0.18 & 0.961 & 45 \\
\hline $6 I^{\star}$ & Day 1 & 6 & $0 \cdot 110$ & 0.79 & 0.847 & 22 \\
\hline 6 I, II, III & All days:+ & 12 & $0 \cdot 119$ & 0.09 & 0.898 & 26 \\
\hline $12^{\star}$ & Day 1 & 8 & 0.075 & $0 \cdot 28$ & 0.834 & 40 \\
\hline & Day 2 & 7 & 0.063 & $0 \cdot 10$ & 0.959 & 50 \\
\hline & All days + & 8 & 0.070 & 0.09 & 0.957 & 45 \\
\hline 2 and 12 & All days + & 31 & 0.068 & 0.14 & 0.963 & 46 \\
\hline
\end{tabular}

*One working week.

†More than one working week.

$\ddagger$ Correlations have been based on the highest airborne benzene concentration and corresponding urinary S-PMA concentration of each operator during the specific study.

ranged from 22 to $55 \mu \mathrm{g} / \mathrm{g}$ creatinine. The most reliable relations were established from data generated from studies 2 and 12 . In study 1 , the measurement of airborne benzene had been rather inaccurate (steps of $0.5 \mathrm{mg} / \mathrm{m}^{3}$ ) and in study 6 most samples had been collected about two hours before the end of an eight hour shift, resulting in lower SPMA concentrations at similar airborne benzene concentrations than in studies 2 and 12. For the assessment of an ultimate regression line from the studies reported here, the 31 data points from studies 2 and 12 (all days) were therefore used. Table 2 also shows the regression line and the correlation coefficient. Table 3 lists the relation between eight hour TWA exposures to airborne benzene and urinary S-PMA concentrations at the end of an eight hour shift for a group of workers (mean and 95\% CIs). At an eight hour TWA benzene exposure of 1 $\mathrm{ppm}\left(3.25 \mathrm{mg} / \mathrm{m}^{3}\right)$, the average S-PMA concentration in urine samples at the end of the shift was $46 \mu \mathrm{g} /$ $\mathrm{g}$ creatinine, with $95 \%$ CIs (as a group) ranging from 41 to $50 \mu \mathrm{g} / \mathrm{g}$ creatinine. On an individual basis the $95 \% \mathrm{CI}$ ranged from 32 to $59 \mu \mathrm{g} / \mathrm{g}$ creatinine (fig 2).

CORRELATION OF URINARY S-PMA AND PHENOL

The relation between urinary S-PMA and phenol concentrations in samples collected at the end of a shift was determined from 24 workers (seven from study 2; nine from study 3 , and eight from study 10 ) whose urinary S-PMA concentrations were higher than $15 \mu \mathrm{g} / \mathrm{g}$ creatinine (range 15 to $543 \mu \mathrm{g} / \mathrm{g}$ ). Urinary phenol concentrations ranged from 3 to 65 $\mathrm{mg} / \mathrm{g}$ creatinine. A highly significant correlation was found between the two parameters (coefficient of correlation 0.945 ). Figure 3 shows the regression line. A urinary phenol concentration of $50 \mathrm{mg} / \mathrm{g}$ creatinine corresponds to an eight hour TWA ben- zene exposure of $10 \mathrm{ppm}^{17}$; the average urinary SPMA concentration is then $383 \mu \mathrm{g} / \mathrm{g}$ creatinine $(95 \%$ CI $339-427 \mu \mathrm{g} / \mathrm{g}$ creatinine).

\section{Discussion}

For the validation of the urinary S-PMA test, which Stommel $e t a l^{\prime}$ claimed to be a sensitive and specific test for monitoring low levels of exposure to benzene, 12 separate investigations have been carried out in three types of industrial settings-namely, chemical manufacturing plants, oil refineries, and natural gas production plants. Workers' exposures to benzene were lowest in oil refineries and generally below the detection limit of $0.1 \mathrm{mg} / \mathrm{m}^{3}$ (eight hour TWA) in air. Corresponding urinary S-PMA concentrations were mostly below the detection limit of 1 to $5 \mu \mathrm{g} / \mathrm{g}$ creatinine. The range of benzene exposures was higher in workers engaged in chemical manufacturing plants where benzene was used or produced and in workers engaged in cleaning of tanks or installations containing gas condensate. Urinary S-PMA concentrations in these workers were generally higher at the end of the shift compared with the

Table 3 Relation between exposure to airborne benzene and urine S-PMA excretion

\begin{tabular}{|c|c|}
\hline $\begin{array}{l}\text { Airborne benzene } \\
\text { concentration } \\
\left(\mathrm{mg} / \mathrm{m}^{3},\right. \\
\text { eight hour } T W A)\end{array}$ & $\begin{array}{l}\text { Urinary } S-P M A \\
\text { concentration at the } \\
\text { end of the shift } \\
\text { ( } \mu g / g \text { creatinine) } \\
\text { Mean }(95 \% C I)\end{array}$ \\
\hline $\begin{array}{l}1 \cdot 0 \\
2 \cdot 0 \\
3 \cdot 0 \\
3 \cdot 25(1 \mathrm{ppm}) \\
4 \cdot 0\end{array}$ & $\begin{array}{l}12(10-14) \\
27(24-30) \\
42(38-46) \\
46(41-50) \\
56(52-62)\end{array}$ \\
\hline
\end{tabular}




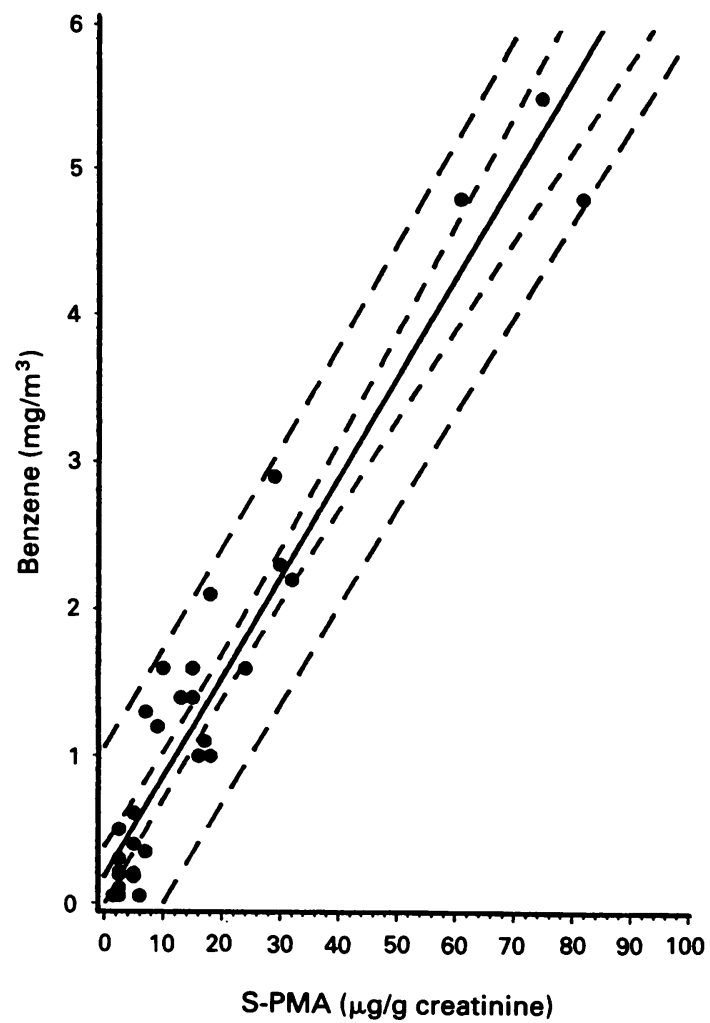

Figure 2 Correlation between respiratory eight hour $T W A$ exposure to benzene and urinary $S-P M A$ concentrations in samples at the end of the shift. The solid line represents the average regression line and the dashed lines the 5\% and $95 \%$ CIs (inner lines on a group basis and outer lines on an individual basis).

beginning. During peak exposures to benzene, urinary S-PMA concentrations up to $543 \mu \mathrm{g} / \mathrm{g}$ creatinine were measured (study 3 ).

The specificity of the S-PMA test has been shown by the low urinary concentrations in control persons (median: $<2 \mu \mathrm{g} / \mathrm{g}$ creatinine) and in samples of workers at the beginning of the working week (median $<5 \mu \mathrm{g} / \mathrm{g}$ creatinine). The benzene uptake from cigarette smoking was too small to influence the S-PMA concentrations. In their preliminary study, Stommel et al carried out S-PMA determinations in 24 hour urine samples. In monitoring studies of industrial populations, the collection of spot urine samples is more practical. To establish the most appropriate sampling time(s), the pattern of urinary excretion of S-PMA in workers exposed to benzene had to be studied. In most workers, S-PMA was excreted in a single phase and the highest S-PMA concentrations were detected in samples at the end of the shift. In some workers the highest S-PMA concentrations were measured at the beginning of the next shift. This difference may be due to interindividual differences in toxicokinetics or to exposure of skin to benzene in the second group of workers, which may have led to a slower absorption of benzene into the body than respiratory exposure. The average urinary $\mathrm{t}^{\frac{1}{2}}$ of elimination was 9.0 (SD 4.5 ) hours. In some workers a tentative second phase of elimination was seen with $t^{\frac{1}{2}}$ of 45 (SD 4 hours). From the $t^{\frac{1}{1}}$ of elimination of about nine hours for most of the workers, it can be calculated that after an eight hour exposure to benzene, some S-PMA (16 to $30 \%$ ) may still be excreted in samples collected at the beginning of the next shift. ${ }^{18}$ This is shown for worker $A$ in fig 1 . It is, however, expected that by analogy with other mercapturic acids with similar $t^{1}$ of elimination, ${ }^{19} 20$ the highest urinary S-PMA concentrations after respiratory exposure to benzene will be reached at the end of an eight hour benzene exposure period.

The percentage of the benzene dose excreted in the urine as S-PMA, calculated from S-PMA in samples collected at the beginning and the end of a shift

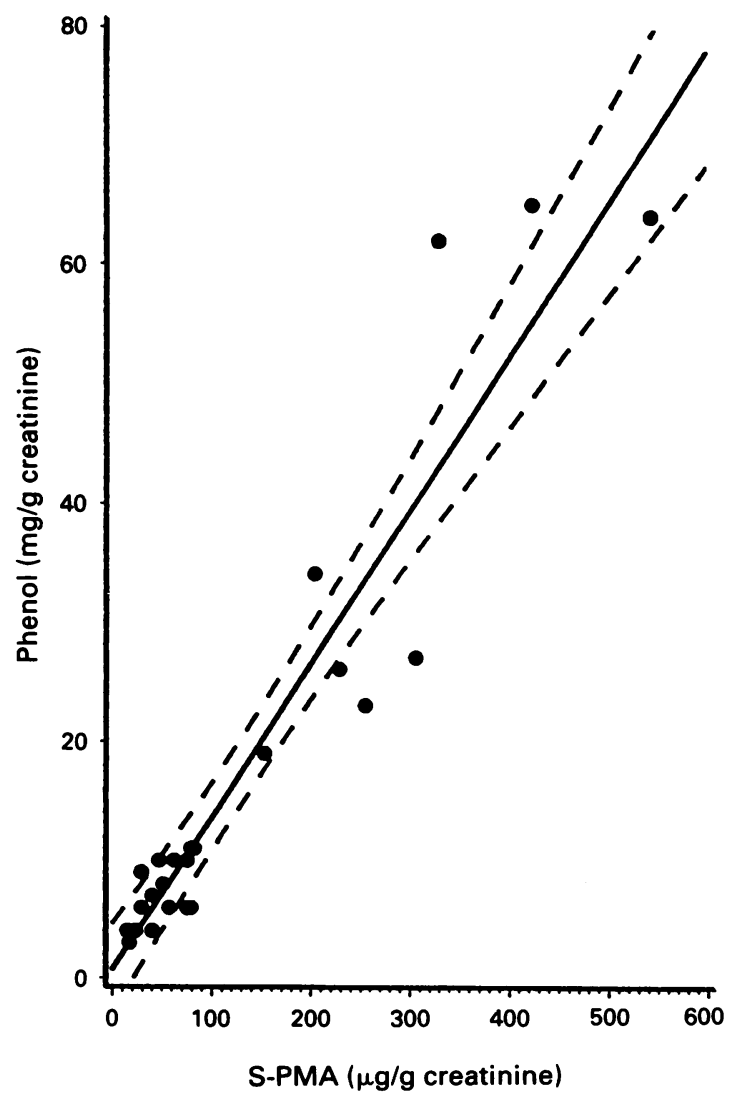

Figure 3 Correlation between urinary phenol and $S$ $P M A$ concentrations in samples at the end of the shift. The regression line with $95 \%$ CIs is shown. 
during several consecutive days, was on average $0.11 \%$. A higher conversion was found by Stommel et al (about $0.9 \%$ ). ${ }^{9}$ These authors made calculations on S-PMA excreted in 24 hour urine samples, which is more accurate. Nevertheless, the low percentage of benzene excreted as S-PMA in humans in comparison with other species (rats, mice) was confirmed.

The relation between exposure to airborne benzene and urinary S-PMA concentrations in end of shift samples could be assessed in four of the 12 studies reported here. Strong correlations were found in all of these four studies. There was reasonable agreement in the regression lines of airborne benzene and urinary S-PMA between the four studies taking into consideration that the studies had been carried out in different locations with different methods of personal air sampling. From the ultimate regression line (fig 2 ) it can be calculated that for an eight hour benzene exposure of $1 \mathrm{ppm}\left(3.25 \mathrm{mg} / \mathrm{m}^{3}\right)$ the average S-PMA concentration amounts to $46 \mu \mathrm{g} /$ $\mathrm{g}$ creatinine with $95 \%$ CIs between 41 and $50 \mu \mathrm{g} / \mathrm{g}$ creatinine. This means that at a concentration of $S$ PMA $41 \mu \mathrm{g} / \mathrm{g}$ creatinine in end of shift samples, the average airborne benzene exposure during the eight hour working day, with $95 \%$ confidence, is below 1 ppm. This limit will be exceeded with $95 \%$ confidence at a urinary S-PMA concentration of $50 \mu \mathrm{g} / \mathrm{g}$ creatinine.

Urinary concentrations greater than $10 \mu \mathrm{g} / \mathrm{g}$ creatinine (twice the limit of detection) are considered to result from exposures to benzene and from the ultimate regression line this concentration corresponds to an eight hour exposure to airborne benzene of $0.3 \mathrm{ppm}\left(1 \mathrm{mg} / \mathrm{m}^{3}\right)$.

Strong correlations were also found between urinary S-PMA and phenol concentrations. The regression line (fig 3) shows that at a phenol concentration of $50 \mathrm{mg} / \mathrm{g}$ creatinine, corresponding to an eight hour exposure to benzene of $10 \mathrm{ppm}^{17}$ the average S-PMA concentration amounts to $383 \mu \mathrm{g} / \mathrm{g}$ creatinine with $95 \%$ CIs between 339 and $427 \mu \mathrm{g} / \mathrm{g}$ creatinine. Thus exposure to $1 \mathrm{ppm}$ benzene (eight hour) will produce an average urinary S-PMA concentration of $38 \mu \mathrm{g} / \mathrm{g}$ creatinine, which corresponds well with the $46 \mu \mathrm{g} / \mathrm{g}$ creatinine determined in a direct way from measurements of airborne benzene. The ratio of urinary phenol and S-PMA concentrations was calculated for 13 of the 24 workers who had been irrcluded in the above correlation study and whose urinary phenol concentrations were equal to or higher than $10 \mathrm{mg} / \mathrm{g}$ creatinine. None of these workers had background urinary phenol higher than $3 \mathrm{mg} / \mathrm{g}$ creatinine. The average ratio (in end of shift samples) was 140 (SD 36), which contrasts with the ratios between 3.2 and 6.4 in 32 hour urine samples of rats reported by Stommel et al..$^{9}$ This may indicate that the biotransformation of benzene into phenolic compounds in relation to S-PMA is more important in humans than in rats, which is not surprising in view of the lower activity of microsomal gluthathione S-transferase in humans. From this it may also be expected that the potentially toxic metabolite hydroquinone, believed to be a secondary metabolite of phenol, ${ }^{1}$ is formed in a greater proportion in humans than in rats.

Several groups have recently reported on the determination of trans:trans-muconic acid, another potentially toxic benzene metabolite, in the urine of workers exposed to benzene..$^{10-12}$ So far, however, it has not been possible to achieve the sensitivity reached with the S-PMA test. Also, the occurrence of background trans:trans-muconic acid concentration of dietary origin may limit its use at low benzene exposures. ${ }^{11}$

In conclusion, our study has confirmed the preliminary findings of Stommel et al, ${ }^{9}$ that the determination of urinary S-PMA is a sensitive and specific test for measuring low levels of benzene exposure. The test is sensitive for monitoring eight hour TWA exposure to benzene of $0.3 \mathrm{ppm}$ and higher. The average S-PMA concentration in end of shift urine samples from workers exposed to $1 \mathrm{ppm}$ of benzene for 8 hours is $46 \mu \mathrm{g} / \mathrm{g}$ creatinine.

Requests for reprints to: Dr N J van Sittert, Shell Internationale Petroleum Maatschappij BV, Health Safety and Environment Division, Biomedical Services, PO Box 162, 2501 AN, The Hague, The Netherlands.

1 Yardley-Jones A, Anderson D, Park DV. The toxicity of benzene and its metabolism and molecular pathology in human risk assessment. $\mathrm{Br} J$ Ind Med 1991;48:437-44.

2 Lauwerys R. Human biological monitoring of industrial chemicals. I. Benzene. Luxembourg: Commission of the European Communities, 1979.

3 Deutsche Forschungsgemeinschaft (DFG). In: Henschler D, ed. Grenzwerte in biologischem Material. Benzol. Weinheim: VCH publishers, 1984.

4 Anon. Occupational exposure to benzene. Federal Register 1987;52 (176): 34460-578.

5 Deutsche Forschungsgemeinschaft (DFG). Maximum concentrations at the workplace and biological tolerance values for working materials. Weinheim: VCH publishers, 1991.

6 Dutch Expert Group of Occupational Standards, Rapport inzake grenswaarde benzeen. Ministry of Social Affairs: DirectoraatGeneraal van de Arbeid, RA 5/89, 1989.

7 Perbellini L, Faccini GB, Pasini F, et al. Environmental and occupational exposure to benzene by analysis of breath and blood. $B r J$ Ind Med 1988;45:345-52.

8 Angerer J, Scherer G, Schaller KH, Müller J. The determination of benzene in human blood as an indicator of environmental exposure to volatile aromatic compounds. Fresenius Journal of Analytical Chemistry 1991;339:740-2.

9 Stommel P, Muller G, Stucker W, Verkoyen C, Schöbel S, Norpoth K. Determination of S-phenylmercapturic acid in the urine-an improvement of the biological monitoring of benzene exposure. Carcinogenesis 1989;10:279-82.

10 Inoue $\mathrm{O}$, Seiji $\mathrm{K}$, Nakatsuka $\mathrm{H}$, Watanabe $\mathrm{T}$, et al. Urinary $\mathrm{t}, \mathrm{t}-$ muconic acid as an indicator of exposure to benzene. $\mathrm{Br} J$ Ind Med 1989;46:122-7.

11 Ducos P, Gaudin R, Robert A, Francin JM, Maire C. Improvement in HPLC analysis of urinary trans:transmuconic acid, a promising substitute for phenol in the 
assessment of benzene exposure. Int Arch Occup Environ Health 1990;62:529-34.

12 Bechtold WE, Lucier G, Birnbaum LS, Yin SN, Li GL, Henderson RF. Muconic acid determinations in urine as a biological exposure index for workers occupationally exposed to benzene. Am Ind Hyg Assoc J 1991;52:473-8.

13 Van Haaften AB, Sie ST. The measurement of phenol in urine by gas chromatography as a check on benzene exposure. $\mathrm{Am}$ Ind Hyg Assoc $J$ 1965;26:52-8.

14 Larsen K. Creatinine assay by a reaction-kinetic principle. Clin Chim Acta 1972;41:209-14.

15 National Institute for Occupational Safety and Health. Manual of analytical methods, 2nd. ed. Vol 3, method S311. Cincinnati: DHEW (NIOSH) publication 77-157C, 1977. (DHEW (NIOSH) Back up data report, benzene, method S311.)

16 Doctor JH, Zielhuis $\mathrm{R}$, Phenol excretion as a measure of occupational exposure. Ann Occup Hyg 1967;10:317-36.

17 American Conference of Governmental Industrial Hygienists. Threshold limit values for chemical substances and physical agents and biological exposure indices. 1991-1992. Cincinnati: ACGIH, 1992.

18 Rowland M, Tozer TN. Clinical pharmacokineticsConcepts and applications. Philadelphia: Lea and Febiger, 1980:174-7.

19 Van Welie RTH, Van Duijn P, Brouwer DH, Van Hemmen JJ, Brouwer EJ, Vermeulen NPE. Biological monitoring of Zand $\mathrm{E}$ - 1,3-dichloropropene by measurement of the urinary excretion of two mercapturic acid metabolites in the Dutch flowerbulb culture. Arch Environ Contam Toxicol 1991;20:612.

20 Jakubowski M, Linhart I, Pielas G, Kopecky J. 2-cyanoethylmercapturic acid (CEMA) in the urine as a possible indicator of exposure to acrylonitrile. $\mathrm{Br} J$ Ind Med 1987;44:834-40.

Accepted 29 June 1992.

\section{Destruction of manuscripts}

From 1 July 1985 articles submitted for publication will not be returned. Authors whose papers are rejected will be advised of the decision and the manuscripts will be kept under security for three months to deal with any inquiries and then destroyed. 